\title{
Solving K-obnoxious Facility Location Problem on A Plane
}

\section{U.K. Bhattacharya}

Indian Institute of Management Indore, Prabandh Sikhar, 453556, MP, India

\begin{abstract}
In this paper k-obnoxious facility location problem has been modeled as a pure planner location problem. Area restriction concept has been incorporated by inducting a convex polygon in the constraints set. A linear programming iterative algorithm for k- obnoxious facility locations has been developed. An upper bound has been incorporated in the algorithm to get the optimal solution. Also the concept of upper bound has reduced the number of linear programming problems to solved in the algorithm. Rectilinear distance norm has been considered as the distance measure as it is more appropriate to the various realistic situations.
\end{abstract}

Keywords: Obnoxious Facility Location; Iterative Algorith; Rectilinear Distance Norm

\section{Introduction}

For service facility location problems when the costs are the increasing function of distance, it is reasonable to consider either minimum of the sum of distances or the weighted distances. On the other hand, for some vital facilities it may be desired to minimize the maximum distances. However, there are types of location situations where cost decreases as distance increases and is named in the literature as obnoxious or undesirable facility location problem.

Location theory can be traced back as far as the $17^{\text {th }}$ century and much work has been done in this area during last 60 years. However undesirable facility location has received less attention from operations researchers. The earliest reference we can find, in the operations research literature that deals with semi desirable facility location models dates back to 1975 , Golden and Dearing ${ }^{[9]}$. Using the rough estimates, approximately $2 \%$ of the location literature deals with obnoxious facility location (Erkut \& Neuman ${ }^{[6]}$ )

Erkut and Neuman $\left.{ }^{[6}\right]$ have mentioned that one explanation for the imbalance may be that the undesirable facility is the byproduct of technology and industrialization. Location of nuclear reactor, power plants, dump sites, mega-airports are all problems of $20^{\text {th }}$ century. On the other hand the desirable facility such as schools, college, hospitals are the problems of centuries. There are environmental issues which should be looked for undesirable facility location in the society. Hansen et. al. ${ }^{[10]}$ point out that the French Government choose to locate half of the country's nuclear power plants along the Atlantic coast line and German and Belgium broader, at a great distance from the large population centers.

In the location literature many people have worked on 1-MAXIMIN criterion with Euclidean distances. Shamos ${ }^{[15]}$ defines the unweighted 1-MAXIMIN problem as the largest empty circle problem in $\mathrm{R}^{2}$ and provides an algorithm for solving that problem. Dasarathy and White ${ }^{[3]}$ extended the unweighted maximin problem to a higher dimensional space and a convex feasible region. They provide an algorithm for a three dimensional space. Drezner and Wesolowsky[4] present a solution to a 1-maximin problem assuming a feasible region which is the intersection of the circles of prescribed radii whose centers are existing facility points. Melachrinoudis and Cullinane ${ }^{[12]}$ solved 1-maximin problem for the case of non-convex feasible region $\mathrm{S}$ in the presence of forbidden circles.

Drezner and Wesolowsky ${ }^{[5]}$ first introduced the rectilinear 1-maximin problem for locating an obnoxious facility. They developed a solution procedure by dividing the feasible region into rectilinear sub regions and solving a linear programming problem for each of these sub regions. Melachrinoudis ${ }^{[9]}$ proved several properties of the optimal solution, developed elimination strategies for each of the sub regions and solved the duals of the LPs for the remaining sub-

Copyright (C) 2018 Utpal Kumar Bhattacharya

doi: $10.24294 /$ tm.v1i2.605

EnPress Publisher LLC.This work is licensed under the Creative Commons Attribution-NonCommercial 4.0 International License (CC BY-NC 4.0). http://creativecommons.org/licenses/ by/4.0/ 
regions. Mehrez et al. ${ }^{[14]}$ suggested an improvement of Drezner and Wesolowsky's algorithm, based on bounds, which reduces the size as well as the number of sub problems to be solved.

In the generic single undesirable facility location models given above, the decision maker wishes to locate the new facility such that some measure of the distances between the new and the existing facilities is maximized. Multiple obnoxious facility location problem is not extensively studied in the literature. We are aware of very few studies on planar multi-facility maximin models. Some of the works on multi-facility maximin problems on networks are by ${ }^{[2,11,7,16]}$

Gianikkos and $\mathrm{Appa}^{[1,8]}$ have studied the rectilinear version of the weighted 2- obnoxious facility location problem, and present an algorithm based on binary search for its solution Tamir ${ }^{[16]}$ proved that when $\mathrm{k}$, the number of obnoxious facilities, is part of the input then the above maximin k-obnoxious facility location model is strongly NP- hard even in the one- dimensional case. Arie Tamir ${ }^{[17]}$ has discussed the problem of locating two new facilities in $\mathrm{S}$ and presented a sub quadratic algorithm.

In this present investigation k-obnoxious facility location model has been designed. Area restriction concept has been incorporated so that the facility to be located should be within certain restricted area. Incorporation of the area restriction has been implemented by inducting a convex polygon in the feasible region. A linear programming iterative algorithm has been developed.

Mathematical model formulation for the multiple obnoxious facility problems has been given in section 2 . Algorithm has been designed in sections 3. A numerical example has been presented in section 4. Conclusion and future scope are given section 5 .

\section{Model Formulation}

Let $\left(a_{j}, b_{j}\right), \mathrm{i}=1,2, \ldots, \mathrm{r}$, be the location of the ith existing facility and $\left(x_{j}, y_{j}\right), \mathrm{j}=1,2, \ldots \mathrm{n}$ are the co-ordinates of the points to be located. The multi-facility formulation of the problem.

P1

$$
\operatorname{Maximize}\left[\operatorname{Min}_{1 \leq \mathrm{j}<\mathrm{k} \leq \mathrm{n}} U_{j}^{K} d\left(X_{j}, P_{i}\right), \operatorname{Min}_{1 \leq i \leq r, 1 \leq j \leq n} W_{i}^{j} d\left(X_{j}, X_{k}\right)\right]
$$

Subject to

$$
c_{p} x_{j}+d_{p} y_{j} \leq e_{p}, \mathrm{p}=1,2, \ldots, 1, \mathrm{j}=1,2, \ldots, \mathrm{n} .
$$

\begin{tabular}{|c|c|}
\hline 01 & $\left(a_{j}, b_{j}\right), \mathrm{i}=1,2, \ldots, \mathrm{r}$, be the location of the ith existing facility. \\
\hline 02 & $\left(x_{j}, y_{j}\right), \mathrm{j}=1,2, \ldots \mathrm{n}$ are the co-ordinates of the points to be located. \\
\hline 03 & $\begin{array}{l}W_{i}^{j}=\text { Weights assigned to the demand points } \mathrm{i} \text { corresponding to the facility points } \mathrm{j} \text { for } \mathrm{i}= \\
1,2 \ldots \mathrm{r} \text { and } \mathrm{j}=1,2, \ldots, \mathrm{n} \text {. }\end{array}$ \\
\hline 04 & $U_{J}^{K}=$ weights corresponding to the facility points $1,2, \ldots, \mathrm{n}$. \\
\hline 05 & 1 be the number of constraints. \\
\hline 06 & $d\left(X_{j}, P_{i}\right)$ represent the distance between the locations of new facility $\mathrm{j}$ and existing facility $\mathrm{i}$. \\
\hline 07 & $d\left(X_{j}, X_{k}\right)$ be the distances between the new facilities $\mathrm{j}$ and $\mathrm{k}$. \\
\hline 08 & $\mathrm{~S}$ be the set of all feasible solutions. \\
\hline 09 & $c_{p}, d_{p}, e_{p}$ are constants for $\mathrm{p}=1,2, \ldots, 1$ \\
\hline 10 & $\mathrm{~m}$ be rectangle for $\mathrm{m}=1,2, \ldots,(\mathrm{r}+1)^{2}$. \\
\hline 11 & $\mathbf{U B}_{\mathrm{m}}$ be the upper bound corresponding to rectangle $\mathrm{m}$ \\
\hline
\end{tabular}

Where the notations are as given in the following table 1.

Table 1. Notations

\section{Generalized Algorithm for k-Obnoxious Facility Location Problem}

Let us consider the grid of lines formed by drawing horizontal and vertical lines through every demand point 
$\left(a_{j}, b_{j}\right)$. This will form $(\mathrm{r}+1)^{2}$ rectangular regions some of them are bounded by infinity. The mathematical formulation for the problem for a given rectangular region, $\mathrm{m}$, is as given below.

P2

$$
\text { Maximize } Z_{1}
$$

Subject to,

$$
\begin{gathered}
W_{i}^{j}\left[\left|\left(x_{j}-a_{i}\right)\right|+\left|\left(y_{j}-b_{i}\right)\right|\right] \geq Z_{1}, \mathrm{i}=1,2, \ldots \mathrm{r}, \mathrm{j}=1,2, \ldots, \mathrm{n} \text { for all } \mathrm{j} \text { in } V_{\mathrm{i}} . \\
U_{j}^{k}\left[\left|\left(x_{j}-x_{k}\right)\right|+\left|\left(y_{j}-y_{k}\right)\right|\right] \geq Z_{1}, \mathrm{i}=1,2 \ldots . \mathrm{r} ; \mathrm{j}=1,2, \ldots, \mathrm{n} \\
Z_{1} \leq \mathbf{U} \mathbf{B}_{\mathrm{m}} \\
c_{p} x_{p}+d_{p} y_{p} \leq e_{p}, \mathrm{p}=1,2, \ldots, 1
\end{gathered}
$$

Let $\mathbf{U B}_{\mathrm{m}}$ is the upper bound corresponding to the rectangle $\mathrm{m}$.

To find the upper bound inside rectangle $\mathrm{m}$ we use procedure I

\subsection{Procedure-1}

The maximum value of $Z_{1}$ on $\mathrm{m}$ is as given below

$$
\begin{aligned}
& \mathrm{Z}_{\mathrm{m}}=\underset{\left(x_{j}, y_{j}\right) \in m}{\operatorname{Max}}\left\{\operatorname{Min}_{i} w_{i}^{j}\left(\left|\mathrm{x}_{\mathrm{j}}-\mathrm{a}_{\mathrm{i}}\right|+\left|\mathrm{y}_{\mathrm{j}}-\mathrm{b}_{\mathrm{i}}\right|\right)+\right. \\
& \left.\quad U_{j}^{k}\left(\left|\mathrm{x}_{\mathrm{j}}-\mathrm{x}_{\mathrm{k}}\right|+\left|\mathrm{y}_{\mathrm{j}}-\mathrm{y}_{\mathrm{k}}\right|\right)\right\} \\
& \leq \operatorname{Min}_{i}\left\{\underset{\left(x_{j}, y_{j}\right) \in m}{\operatorname{Max}} w_{i}^{j}\left(\left|\mathrm{x}_{\mathrm{j}}-\mathrm{a}_{\mathrm{i}}\right|+\left|\mathrm{y}_{\mathrm{j}}-\mathrm{b}_{\mathrm{i}}\right|\right)+\right. \\
& \left.U_{j}^{k}\left(\left|\mathrm{x}_{\mathrm{j}}-\mathrm{x}_{\mathrm{k}}\right|+\left|\mathrm{y}_{\mathrm{j}}-\mathrm{y}_{\mathrm{k}}\right|, \text { for all possible } \mathrm{k} \neq \mathrm{j}\right)\right\}
\end{aligned}
$$

The maximum inside rectangle $\mathrm{m}$ must occur on $\mathrm{V}$, where $\mathrm{V}$ is the set of four vertices of the rectangle ( some of these vertices may be at infinity). Hence, an upper bound on $Z_{1}$ is

$$
\begin{gathered}
\mathbf{U} \mathbf{B}_{\mathrm{m}}=\operatorname{Min}_{i}\left\{\begin{array}{c}
\operatorname{Max} \\
\left(x_{j}, y_{j}\right) \in m
\end{array} w_{i}^{j}\left(\left|\mathrm{x}_{\mathrm{j}}-\mathrm{a}_{\mathrm{i}}\right|+\left|\mathrm{y}_{\mathrm{j}}-\mathrm{b}_{\mathrm{i}}\right|\right)+\right. \\
\left.U_{j}^{k}\left(\left|\mathrm{x}_{\mathrm{j}}-\mathrm{x}_{\mathrm{k}}\right|+\left|\mathrm{y}_{\mathrm{j}}-\mathrm{y}_{\mathrm{k}}\right| \text {, for all possible } \mathrm{k} \neq \mathrm{j} \text { in } \mathrm{V}\right)\right\}
\end{gathered}
$$

\subsection{Procedure-2}

To find $x_{j}=x_{L_{j}}$ for $\mathrm{j}=1,2,3, \ldots \mathrm{n}$, the lower limit for $x_{j}$, solve a linear programming problem with $x_{j}$ as the objective to be minimized and the constraints $c_{p} x_{j}+d_{p} y_{j} \leq e_{p}, \mathrm{p}=1,2, \ldots 1, \mathrm{j}=1,2, \ldots \mathrm{n}$. Maximizing $x_{j}$ will give 
${ }^{x} U_{j}$ which define the upper limit. The lower and the upper limit for $y_{j}={ }^{y} L_{j}$ and $y_{j}={ }^{y} U_{j}$ are found by minimizing $y_{j}$ and maximizing $y_{j}$ respectively.

Let us consider the rectangle $\mathrm{m}$ defines by the lines $x_{j}=x_{j i_{1}}, \quad x_{j}=x_{j i_{2}} \quad x_{j}=x_{j i_{3}} \quad x_{j}=x_{j i_{4}}$ where $x_{j i_{1}}<x_{j i_{2}}$ and $x_{j i_{3}}<x_{j i_{4}}$. Also define the segments $\left[x_{j L}^{i}, x_{j U}^{i}\right]$ and $\left[y_{j L}^{i}, y_{j U}^{i}\right]$ where $x_{j L}^{i}<x_{j U}^{i} y_{j L}^{i}<y_{j U}^{i}$. These are the points of the line $y_{j}=y_{j i}$ and $x_{j}=x_{j i}$.respectively.

Theorem-3.2: If all the conditions hold then there is no feasible point inside rectangle $\mathrm{m}$.

$$
\begin{aligned}
& \text { (1) }{ }^{{ }^{i} 1_{j L}>y_{j i}} \quad \text { or }{ }^{i_{j}}<y_{j i_{3}} \\
& y_{j L}^{i_{2}}>y_{j i_{4}} \quad y_{j U}^{i}<y_{j i} \\
& x_{j L}^{i_{3}}>x_{j i_{2} \text { or }}{ }_{j U}^{i_{3}}<y_{j i_{1}} \\
& x_{j L}^{i_{4}}>x_{j i_{2} \text { or }} x_{j U}^{i_{4}}<y_{j i}
\end{aligned}
$$

Proof: As trivially follows

Now two non-linear inequality constraints (3.2) and (3.3) can be broken down, with inequality relations.

\subsection{Inequality Relation-1: In equation 3.2 is equivalent to four set of constraints as follows}

$$
x_{j}+y_{j}-a_{i}-b_{i}-\left(Z_{1} / w_{i}^{j}\right)>0
$$

Or

$$
x_{j}-y_{j}-a_{i}+b_{i}-\left(Z_{1} / w_{i}^{j}\right)>0
$$

Or

$$
x_{j}-y_{j}-a_{i}+b_{i}+\left(Z_{1} / w_{i}^{j}\right)<0
$$

Or

$$
-x_{j}-y_{j}+a_{i}+b_{i}-\left(Z_{1} / w_{i}^{j}\right)>0
$$

Proof.

In equality relation 3.2

$$
\begin{array}{r}
\left|\left(x_{j}-a_{i}\right)\right|+\left|\left(y_{j}-b_{i}\right)\right| \geq\left(Z_{1} / w_{i}^{j}\right) \\
\Rightarrow\left|x_{j}-a_{i}\right| \geq\left(Z_{1} / w_{i}^{j}\right)-\left|y_{j}-b_{i}\right| \\
\Rightarrow \quad\left(Z_{1} / w_{i}^{j}\right)-\left|y_{j}-b_{i}\right|_{<}\left(x_{j}-a_{i}\right)
\end{array}
$$

Or

$$
-\left(Z_{1} / w_{i}^{j}\right)+\left|y_{j}-b_{i}\right|>\left(x_{j}-a_{i}\right)
$$

From equation (1) above

$$
\begin{gathered}
\left|y_{j}-b_{i}\right|>-x_{j}+\left(Z_{1} / w_{i}^{j}\right)+a_{i} \\
y_{j}-b_{i}>-x_{j}+\left(Z_{1} / w_{i}^{j}\right)+a_{i}
\end{gathered}
$$

Or

$$
y_{j}-b_{i}<x_{j}-\left(Z_{1} / w_{i}^{j}\right)-a_{i}
$$




$$
x_{j}+y_{j}-a_{i}-b_{i}-\left(Z_{1} / w_{i}^{j}\right)>{ }_{0}
$$

Or

$$
x_{j}-y_{j}-a_{i}+b_{i}-\left(Z_{1} / w_{i}^{j}\right)>0
$$

Similarly from equation (2)

$$
x_{j}-y_{j}-a_{i}+b_{i}+\left(Z_{1} / w_{i}^{j}\right)<0
$$

Or

$$
-x_{j}-y_{j}+a_{i}+b_{i}-\left(Z_{1} / w_{i}^{j}\right)>0
$$

By associative law for addition we can write in equation (2.4) is equivalent to (a)or (b) or (c) or (d).

This completes the proof.

\subsection{Inequality relation-2: In equation 3.3 is equivalent to four set of constraints as follows}

$$
x_{j}+y_{j}-x_{k}-y_{k}-\left(Z_{1} / U_{j}^{k}\right)>0 \text {; }
$$

Or

$$
x_{j}-y_{j}-x_{k}+y_{k}-\left(Z_{1} / U_{j}^{k}\right)>0 \text {; }
$$

Or

$$
x_{j}-y_{j}-x_{k}+y_{k}+\left(Z_{1} / U_{j}^{k}\right)<0 \text {; }
$$

Or

$$
-x_{j}-y_{j}+x_{k}+y_{k}-\left(Z_{1} / U_{j}^{k}\right)>0
$$

Proof. Proof follows in the same line as given in in equality relation 1.

Combining in equality relation 1 and inequality relation 2 corresponding to equation (3.2) and (3.3) we get 16 set of alternative in equations as given below.

$$
\begin{aligned}
& C 11: x_{j}+y_{j}-a_{i}-b_{i}-\left(Z_{1} / w_{i}^{j}\right)>0 \\
& D 11: x_{j}+y_{j}-x_{k}-y_{k}-\left(Z_{1} / U_{j}^{k}\right)>0 \\
& \text { or } \\
& C 11: x_{j}+y_{j}-a_{i}-b_{i}+\left(Z_{1} / w_{i}^{j}\right)>0 \\
& D 12: x_{j}-y_{j}-x_{k}+y_{k}-\left(Z_{1} / U_{j}^{k}\right)>0 \\
& \text { or } \\
& C 11: x_{j}+y_{j}-a_{i}-b_{i}+\left(Z_{1} / w_{i}^{j}\right)>0 \\
& D 13: x_{j}-y_{j}-x_{k}+y_{k}+\left(Z_{1} / U_{j}^{k}\right)<0 \\
& \text { or } \\
& C 11: x_{j}+y_{j}-a_{i}-b_{i}+\left(Z_{1} / w_{i}^{j}\right)>0 \\
& D 14:-x_{j}-y_{j}+x_{k}+y_{k}-\left(Z_{1} / U_{j}^{k}\right)>0 \text { for } \mathrm{i}=1,2, \ldots \mathrm{m} ; \mathrm{j}=1,2, \ldots, \mathrm{n}
\end{aligned}
$$




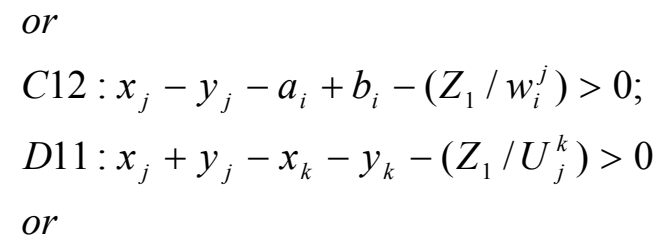

or 


$$
\begin{aligned}
& C 14:-x_{j}-y_{j}+a_{i}+b_{i}-\left(Z_{1} / w_{i}^{j}\right)>0 \\
& D 14:-x_{j}-y_{j}+x_{k}+y_{k}-\left(Z_{1} / U_{j}^{k}\right)>0
\end{aligned}
$$

For all the sixteen sets $I=1,2, \ldots, m$ and $j=1,2, . . n$

The complete algorithm for $\mathrm{k}$ - obnoxious facility location model is as given below.

\subsection{Algorithm}

Step-1 Find the enclosing feasible rectangle.

Step-2 Restrict the grid and rectangles to be considered to those that lie within the enclosing feasible rectangle.

Step-3 Eliminate all infeasible rectangles by theorem-1.

Step-3 Find the upper bound on $Z_{1}$ by using the procedure-1 of section 3. Sort these upper bounds of $Z_{1}$ from largest to smallest.

Step-4 Develop 16 alternative set of in-equality constraints for the non-linear constraints (3.2) and (3.3) as given in in equality relation $3.1 \& 3.2$.

Step-5. Solve the sub problems starting with the rectangle with the highest upper bound on $L_{1}$. Consider constraints corresponding to that rectangle. Take the solution of the sub problem which gives maximum objective function value

Step-6. Stop when the upper bound for the next rectangle is not superior than the solution obtained so far.

\section{Numerical Example}

Let $\mathrm{A}(2,1), \mathrm{B}(3,5), \mathrm{C}(6,9), \mathrm{D}(4,1), \mathrm{E}(9,7)$ be the five demand points on a plane, and $\mathrm{X} 1 \leq 10 ; \mathrm{X} 2 \leq 12 ; \mathrm{Y} 1$ $\leq 9$; Y2 $\leq 11$; are the boundary of the convex feasible region. Let the weights attached to five demand points are $0.30,0.15,0.20,0.10,0.25$ respectively. Also the weights associated corresponding to the two facility points is 0.3

The upper bound corresponding to the twenty feasible rectangles are obtained by procedure 3.1 and are given in the following table.

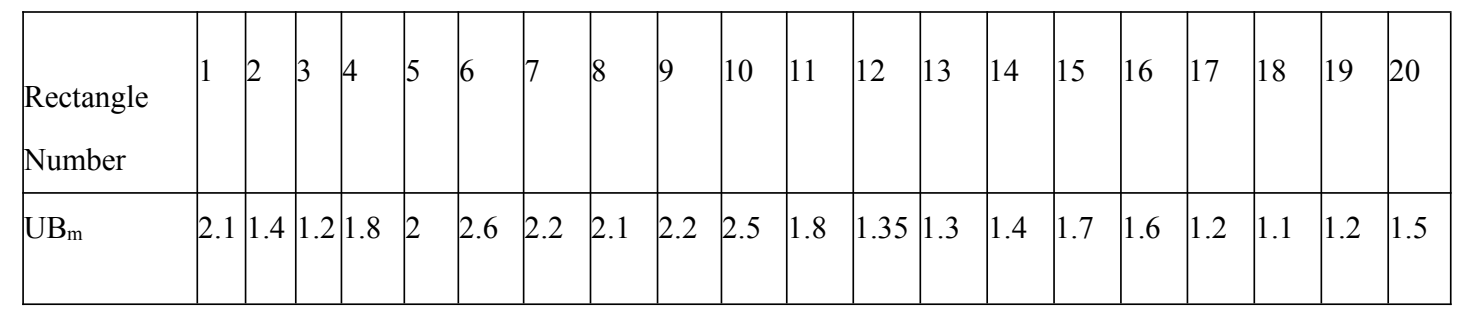

Table 2. Upper bounds for various rectangles

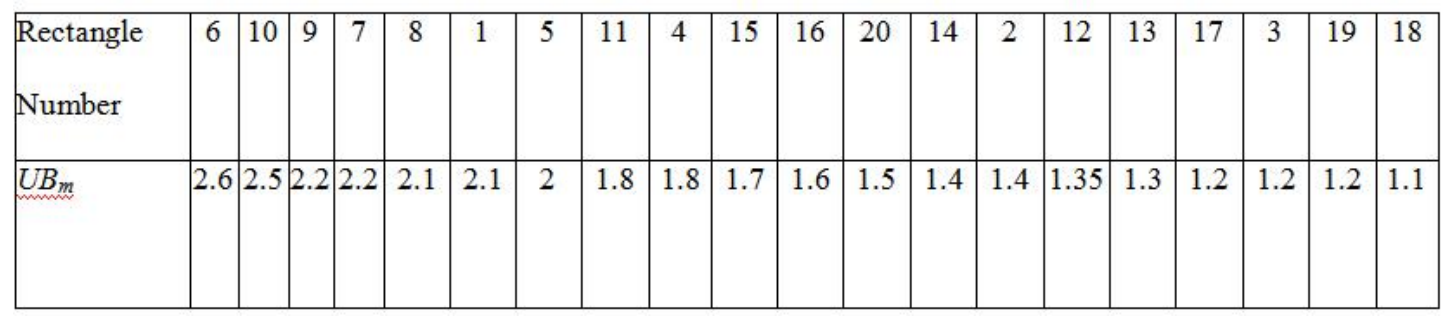

Table 3. Upper bounds in sorted order 
Figure 1

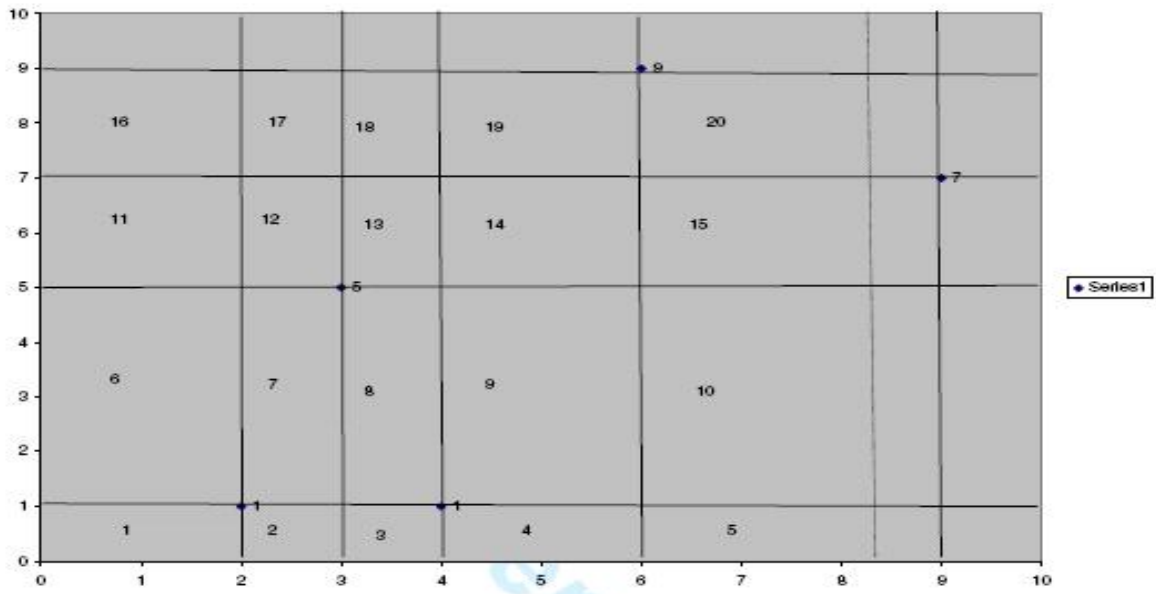

Figure 6.1. Rectangles 1-20.

Mathematical formulation corresponding to the highest upper bound 2.6, corresponding to the rectangle 6 , is as given below.

Here 16 sub problems corresponding to 16 set of inequality relations are formed. Also constraint corresponding to the rectangle 6 is also taken into consideration.

Solution obtained for all 16 sub problems by LINGO-12.0 are as given below.

\begin{tabular}{|c|c|c|c|}
\hline Sub problem & Objective value & Co-ordinates & Remarks \\
\hline SP-1 & & & No Feasible Solution \\
\hline SP-2 & & & -Do- \\
\hline SP-3 & & & -Do- \\
\hline SP-4 & & & -Do- \\
\hline SP-5 & & & -Do- \\
\hline SP-6 & & & -Do- \\
\hline SP-7 & & & -Do- \\
\hline SP-8 & & & -Do- \\
\hline SP-9 & 1.6 & $\begin{array}{l}(\mathrm{x} 1, \mathrm{y} 1)=(2,4.33) \\
(\mathrm{x} 2, \mathrm{y} 2)=(0,1)\end{array}$ & Feasible Solution \\
\hline SP-10 & 1.8 & $\begin{array}{l}(\mathrm{x} 1, \mathrm{y} 1)=(2,1) \\
(\mathrm{x} 2, \mathrm{y} 2)=(0,5)\end{array}$ & -Do- \\
\hline SP-11 & 2.6 & $\begin{array}{l}(\mathrm{x} 1, \mathrm{y} 1)=(2,1) \\
(\mathrm{x} 2, \mathrm{y} 2)=(0,1)\end{array}$ & -Do- \\
\hline SP-12 & 1.8 & $\begin{array}{l}(\mathrm{x} 1, \mathrm{y} 1)=(0,1) \\
(\mathrm{x} 2, \mathrm{y} 2)=(2,5)\end{array}$ & -Do- \\
\hline SP-13 & 0.3 & $\begin{array}{l}(\mathrm{x} 1, \mathrm{y} 1)=(0,2) \\
(\mathrm{x} 2, \mathrm{y} 2)=(0,1)\end{array}$ & -Do- \\
\hline SP-14 & 0.342 & $\begin{array}{l}(\mathrm{x} 1, \mathrm{y} 1)=(0.57,1) \\
(\mathrm{x} 2, \mathrm{y} 2)=(0.142,1.71)\end{array}$ & -Do- \\
\hline SP-15 & 0.4 & $\begin{array}{l}(\mathrm{x} 1, \mathrm{y} 1)=(0,1) \\
(\mathrm{x} 2, \mathrm{y} 2)=(0,1)\end{array}$ & -Do- \\
\hline SP-16 & 0.3 & $\begin{array}{l}(\mathrm{x} 1, \mathrm{y} 1)=(0,1) \\
(\mathrm{x} 2, \mathrm{y} 2)=(1,1)\end{array}$ & -Do- \\
\hline
\end{tabular}

Table 4. Solutions of the sub problems 
Maximum value obtained corresponding to sub problem 11 which is 2.6 . We stop the procedure here as the solution obtained for the subsequent upper bound rectangles cannot dominate the solution obtained so far. Thus the solution is $(\mathrm{x} 1, \mathrm{y} 1)=(2,1),(\mathrm{x} 2, \mathrm{y} 2)=(0,1)$ and $\mathrm{Z} 1=2.6$.

\section{Conclusion and future scope}

- In this paper a k-obnoxious facility location problem has been modeled

- A modified linear programming algorithm has been designed to solve the proposed model..

- Other distance norm such as Euclidean, Geodesic etc. may be considered to model various other situations.

- Models with general feasible regions ( Union of disjoint and non-convex sets) may be considered to model various geographic regions.

\section{References}

1. G. Appa, I. Giannikos, Locating two obnoxious facilities in the plane under the rectilinear metric, LSE OR Working paper LSE 04-69, London School of Econimics, 2004.

2. C.K. Chen, R.S. Garfinkel, The generalized diameter of a graph, Networks 12 (1982) 335-340

3. B. Dasarathy, and L.. White, A Maximin Location Problem, Operations Research, . 28 (1980) 1385-1401.

4. Z. Drezner, and G.O. Wesolowsky, A Maximin Location Problem with Maximum Distance Constraints, AIIE Transaction. 11 (1980) 249-252.

5. Z. Drezner, and G.O. Wesolowsky, Location of an Obnoxious Facility with Rectangular Distance, Journal of Regional Science. 23 (1983) 241-248.

6. Erhan, Erkut and Susan, Neuman, Analytical Models for Locating Undesirable Facilities, European Journal of Operational Research. 40 (1989) 275-291.

7. E. Erkut, The discrete p-dispersion problem, European J. Operations Research, 46 (1990) 48-60.

8. I. Giannikos, Optimal Location of single and multiple obnoxious facilities: algorithms for the MAXIMIN criterion under different norms, PhD Thesis. London School of Economics and Political Sciences, 1993.

9. A.J. Goldman, and P.M. Dearing, Concepts of optimal locations for partially noxious facilities, Bulletin of the Operational Research Society of America, 23/1, (1975), B85

10. P. Hansen, D. Peeters and J.F. Thisse, On the location of an obnoxious facility, Sistemi Unbeni 3, 299-317.

11. M.J. Kuby, Programming models for facility dispersion: the p dispersion and maximum dispersion problems, Geographical Anal. 19 (1987) 315-329.

12. E. Melachrinoudis, and T.P. Cullinane, Locating an Undesirable facility within a Geographical Region Using the Maximin Criterion, Journal of Regional Science. 25 (1985) 115-127.

13. E. Melachrindis An Efficient Computational Procedure for the Rectilinear Maximin Location Problem, Transportation Science. 22 (1988) 217-223.

14. A. Mehrez, Z. Sinuany-Stern, A. Stulman. An Enhancement of the Drezner- Wesolowsky Algorithm for Single Facility Location with Maximin of Rectangular Distance, Journal of Operations Research Society, 37 (1986) 971-977.

15. N. Shamos, Computational Geometry, PhD Dissertation, Department of Computer Science, Yale University. 1977.

16. A. Tamir, Obnoxious facility location on graphs, SIAM j. Discrete Math. 4 (1991) 550-567.

17. A Tamir. Locating Two Obnoxious Facilities using the Weighted Maximin Criterion., Operations Research Letter 34 (2006) 97-105. 